\title{
Amphiphilic Cyclodextrins, Synthesis, Utilities and Application of Molecular Modeling in Their Design
}

\author{
Atena Jabbari and Hamid Sadeghian \\ Additional information is available at the end of the chapter
}

http://dx.doi.org/10.5772/50220

\section{Introduction}

Drug delivery systems that traditionally are used by the patient do not respond the drug delivery's needs of the world. According to the large number of the hydrophilic and hydrophobic drugs, design and synthesis of new drug delivery system seems to be necessary. With the traditional drug delivery systems practically there is no control over the time, location and rate of drug release, in addition to the drug concentration was fluctuated in the blood frequently and may even go beyond the therapeutic dose and less effective and cause more side effects. With the new drug delivery systems that called controlled released drug delivery system, we will be able to control and determine the rate, time and location of drug release. CDs are potential candidate for such a role, because of their ability to change physicochemical and biological properties of guest molecules through the formation of inclusion complexes (Uekama et al,1998). The most common pharmaceutical application of cyclodextrins is to increase the stability, solubility and bioavailibity of drug molecules and other pharmacological benefits,such as the reduction of unwanted side effect (Hedges, 1998).

Cyclodextrins (CD) are macrocyclic oligosaccharides composed of D-(+)-glycopyranosyl units linked $\alpha(1 \rightarrow 4)$. CDs are classified as $\alpha-, \beta$ - and $\gamma$-CD according to the number of glucose units: six, seven and eight, respectively. Cyclodextrins have a truncated cone shape with a hydrophilic exterior and a hydrophobic cavity. A guest molecule of appropriaty size and shape is incorporated into hydrophpbic cavity in aqueous media (Szejtli, 1998).

However, the potential use of CDs in biological system needs amphiphilic properties because natural CDs have relatively low solubility both in water and organic solvents, thus limits their uses in pharmaceutical formulations. Amphiphilic or ionizable cyclodextrins can 
modify the rate or time of drug release and bind to the surface membrane of cells, that may be used for the enhancement of drug absorption across biological barriers.

Amphiphilic cyclodextrins can be obtained by the introduction of lipophilic groups at primary and or secondary face of the CD. Amphiphilic CDs have been shown to form monolayers at the air-water interface (Parot-Lopez, 1992; Greenhall et al, 1995) and micelles in water (Auze'ly-Velty et al, 2000). Different self-organized amphiphilic CDs, such as nanospheres (Skiba et al, 1996), solid-lipid nanoparticles (Dubes, 2003) , liquid crystals (Ling et al, 1993) and vesicles (Ravoo \& Darcy, 2000) were prepared with varying length of hydrophobic chains for their promising properties for farmaceutical applications.

Hydrophilic-hydrpphobic balance, molecular shape and solvation have all been enunciated as important criteria for formation of distinct lyotropic assemblies (Israelachvilli, 1985; Fuhrhop \& Koning, 1994).

A particulary interesting example of self-assembly of amphiphilic CDs in water is bilayer vesicles. CDs vesicles consist of bilayers of CDs, in which the hydrophobic "tails" are directed inward and the hydrophilic macrocycle"head groups" are facing water, thereby enclosing an aqueous interior. Recently, vesicles composed entirely of nonionic, anionic, and cationic amphiphilic CDs was described (Falvey et al, 2005).

Nano capsules and nanospheres were prepared using amphiphilic $\beta$-and $\gamma$-CDs modified on the secondary face by nanoprecipitation and emulsion/solvent evaporated techniques avoiding the use of additional surfactant (Woussidjewe et al, 1996).

The first amphiphilic cyclodextrin were synthesized in 1986 by Kwabata et al. The primary $\mathrm{OH}$-groups of $\beta-\mathrm{CD}$ were made lipophilic with alkyl sulfunyl groups with various length. This amphiphilic CD could form monolayer at the air-water interface (Kawabata et al, 1986).

\section{Synthesis of amphiphilic cyclodextrins}

$\beta$-CDs in synthesis of amphiphilic cyclodextrins was used more than $\alpha$ - and $\gamma$ CDs. Common synthetic path to amphiphilic cyclodextrins was shown in Fig. 1.

\subsection{Alkylated, arylated and lipid -Conjugated CDs}

Synthesis of alkylated $\alpha$ - and $\beta$-CDs and their treatment at air -water interface, have been described by Jurczak et al (Wazynska et al, 2000). Silyl-protected $\alpha$ - or $\beta$-CDs was alkylated then desilated to achievement amphiphilic per-(2,3-di-O-alkyl)-CDs (5) (Fig. 2).

Compound (10) which contain amphiphilic chains, was synthesized from per-amino- $\beta$ CD using peptide chemistry (Imamura et al, 2002) (Fig. 3). Reason of suitable complexation of anilinonaphthalene sulfonic acid can ralativ to presence of Adipicglucamine chains that enhance extension of the cavity in this structure. $\gamma$-CDs derivatives of this family, can complex with two molecules of anthraquinone-2-sulfonate (Ling \& Darcy, 1993) (Fig. 4). 


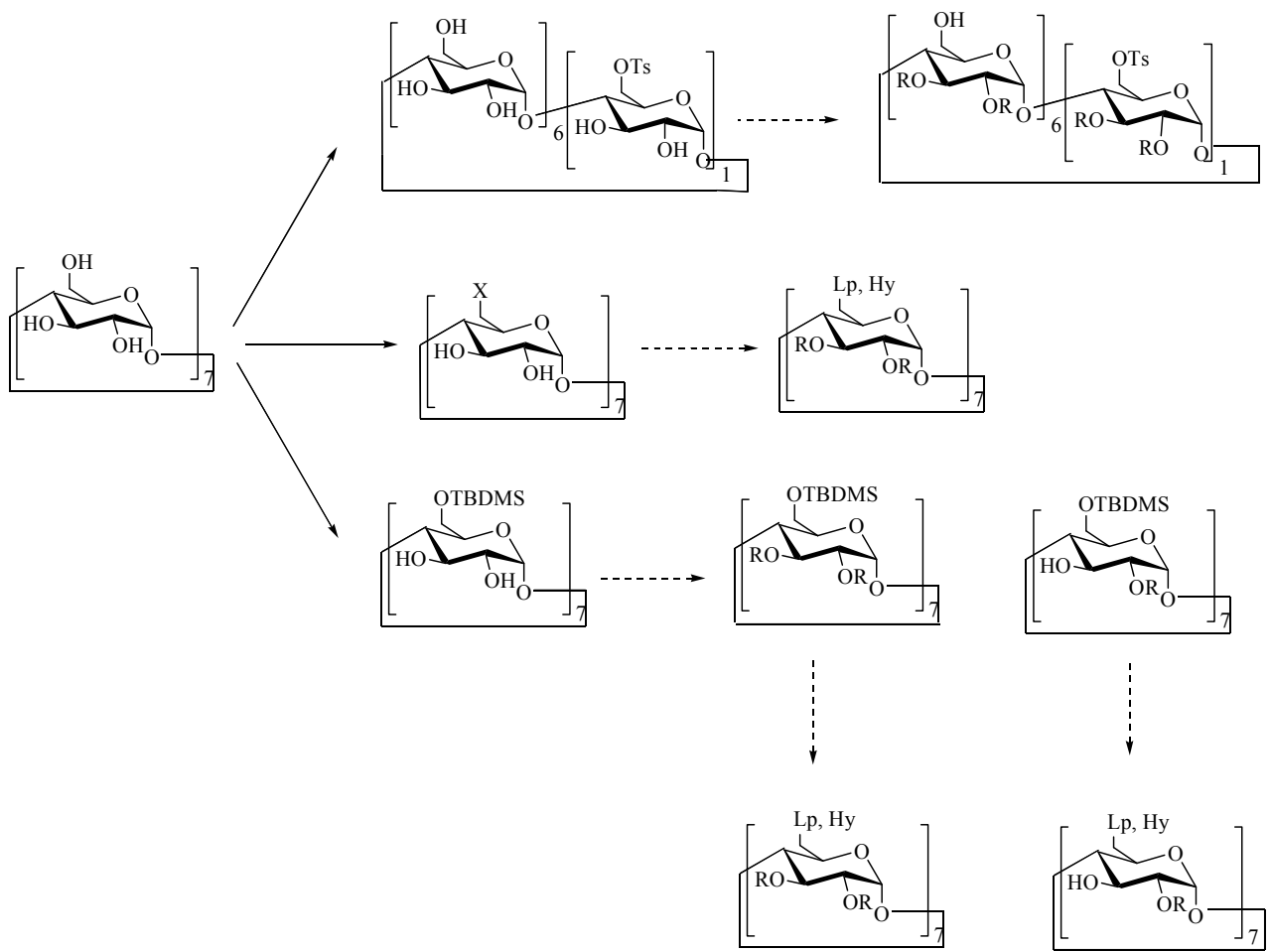

$\mathrm{Lp}=$ =lipophile, Hy=hydrophile; for $\mathrm{Lp}, \mathrm{R}$, is hydrophilic; for $\mathrm{Hy}, \mathrm{R}$, is lipophilic

Figure 1. Common synthetic path to amphiphilic cyclodextrins



(1)

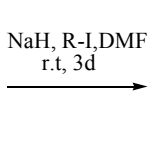

$\mathrm{n}=6$ $\mathrm{n}=7$



(5)

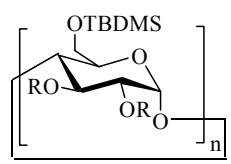

(2)
$\mathrm{Na} / \mathrm{NH}_{3}, \mathrm{NH}_{4} \mathrm{Cl}$, THF

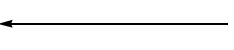



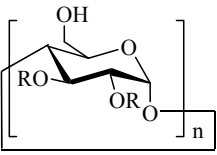

(3)

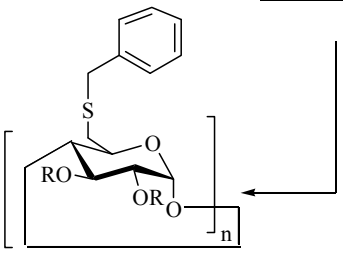

(4)

$\mathrm{R}=\left(\mathrm{CH}_{2}\right)_{4} \mathrm{CH}_{3}$

$\mathrm{R}=\left(\mathrm{CH}_{2}\right)_{5} \mathrm{CH}_{3}$

$\mathrm{R}=\left(\mathrm{CH}_{2}\right)_{6} \mathrm{CH}_{3}$
$\mathrm{PPh}_{3} \mathrm{I}_{2}$, imidazole,

toluene then benzyl

mercaptan

$\mathrm{NaOMe}, \mathrm{DMF}, 60^{\circ} \mathrm{C}, 24 \mathrm{~h}$

Figure 2. Synthesis of alkylated cyclodextrins 


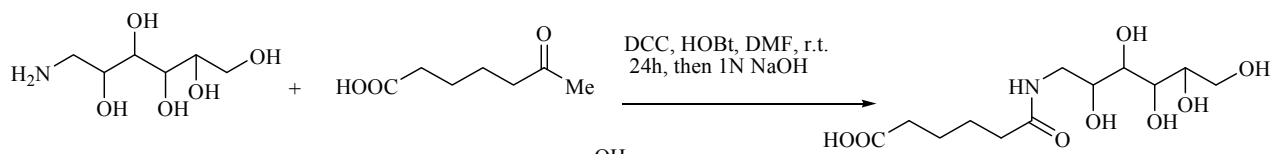

(6)

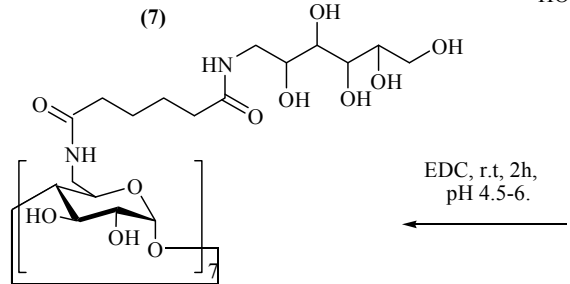

(10)
(8)



(9)

Figure 3. Peptide chemistry was used for synthesis of amphiphilic cyclodextrins<smiles>O=S(=O)(O)c1cccc2cccc(Nc3ccccc3)c12</smiles>

8-Anilino-1-naphtalenesulfonic acid

(11)<smiles>O=C1c2ccccc2C(=O)c2cc(S(=O)(=O)[O-])ccc21</smiles>

Anthraquinone-2-sulfonate

(12)

Figure 4. Structures of two guest molecules for complxation with compound (10)

$\mathrm{Wu}$ and coworkers in 2010 reported the synthesis of new amphiphilic biodegradable $\beta$ cyclodextrin/poly (L-leucine)( $\beta$-CD-PLLA) copolymer by ring-opening polymerization of $\mathrm{N}$ carboxy-L-alanine anhydride in N,N-dimethylformamide(DMF) initiated by mono-6-amino$\beta$-cyclodextrin (Zhang et al, 2010). These compound could self- assemble into nano-micelles in water and could be expected to find application in drug delivery systems (Fig. 5).

A novel thiolated carboxymethyl chitosan-g- $\beta$-cyclodextrin (CMC-g- $\beta$-CD) drug delivery carrier was synthesized by Gong et al (Prabaharan \& Gong, 2008).

Thiolated CMC-g- $\beta$-CD was prepared using two steps. First , carboxymethyl- $\beta$-CD (CM $\beta-$ $\mathrm{CD})$ was grafted onto carboxymethyl chitosan (CMC) using water-soluble 1-ethyl-3-(3dimethylaminopropyl)carbodiimide (EDC) and N-hydroxysuccinimide (NHS) as the condensing agents. Next, the resultant product was further grafted with cycteine methyl ester hydrochloride (CMEH) (Fig. 6).

The drug release showed that thiolated CMC-g- $\beta-C D$ tablets provided a slower release of the entrapped hydrophobic model drug, ketoprofen, than the chitosan control, and the release behavior was influenced by the amounts of thiol groups present on the polymer chains. These results suggest that thiolated CMC-g- $\beta$-CD with improved mucoadhesive 


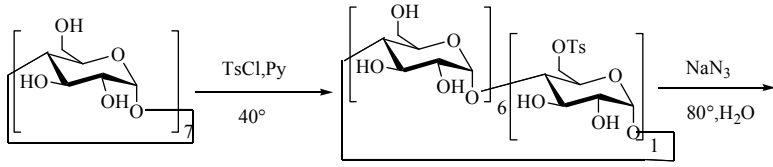

(13)
(14)

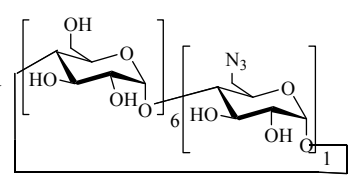

(15)

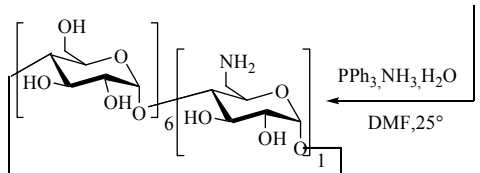

$\mathrm{NH}_{2}-\beta-\mathrm{CD}$

(16)

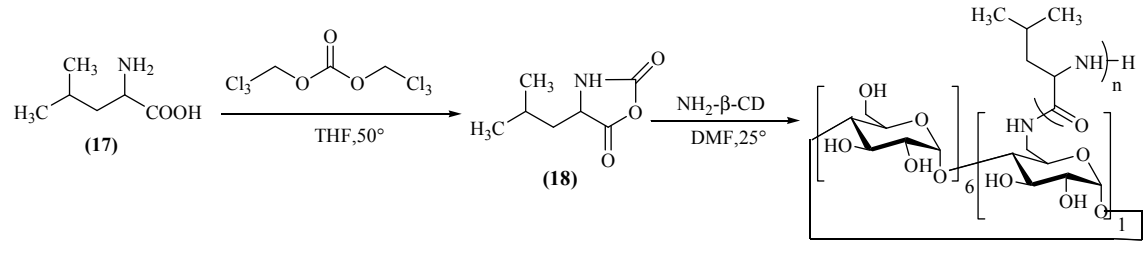

(19)

Figure 5. Synthetic pathway to amphiphilic biodegradable $\beta$-cyclodextrin/poly (L-leucine)( $\beta$-CD-PLLA) copolymer



(20)

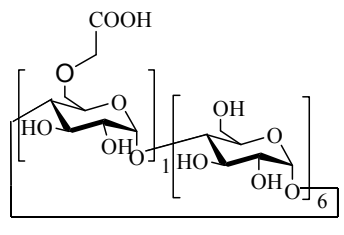

CM- $\beta$-CD

(21)

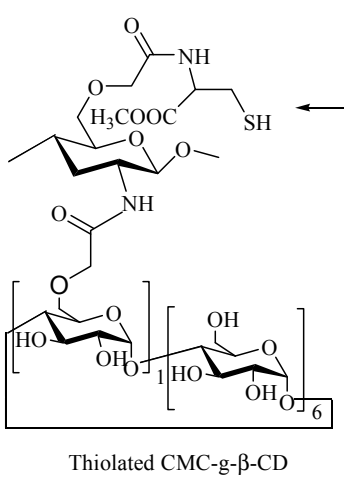

(23)

Figure 6. Preparation of thiolated CMC-g- $\beta$-CD 
properties may potentially become an effective hydrophobic drug delivery system with controlled drug release capability.

Chitosan-cyclodextrin nanosphere were prepared by in situ formation through Michael addition between N-maleated chitosan (NMC) and per-6-thio- $\beta$-cyclodextrin sodium salt in an aqueous medium (Wang et al, 2011). This facil preparation method did not involve any organic solvent and surfactant. Through adjusting the preparation conditions, the nanosphere with a relatively narrow size analyzer. Doxorubicin hydrochloride (DOX-HCl), a water soluble anticancer drug, was loaded in the nanosphere with a high encapsulation efficiency (Fig. 7).

Chloesteryl derivatives of CDs were mostly investigated by Pilard and coworkers. Synthetic pathway of one of them was shown below (Auze'ly-Velty et al, 1999) (Fig. 8).

In 2007, Mallet and coworkers synthesized new derivatives of amphiphilic CDs (Collat et al, 2007). These compound were obtained from reaction between carboxylic acid that derivative of chlosterol with di-amino CDs in presence of DCC and 1-hydroxy benzo tri azol(HoBt). These compounds can act similar to biological membrans (Fig. 9).

\subsection{Oligo(ethylene oxide) amphiphilic CDs}

The first Amphiphilic CD to form bilayer vesicles were reported by Ravoo and Darcy in 2000 (Ravoo \& Darcy, 2000; Mazzaglia et al, 2001; Falvey et al, 2005). Synthesis of them initiated from per-6-bromo and at the result of nucleophilic substituation with the sodium or potassium salt of alkyl thiols, per-alkyl thio CDs were prepared then hydroxyl groups that bind to C-2 of these compounds reacted with an excess of ethylene carbonat and finally average of two units of ethylene glycol were located in this position (C-2 of the CD) (Ravoo \& Darcy, 2000; Mazzaglia et al, 2001 ) (Fig. 10).

This reaction was performed with $\alpha$ - and $\gamma$-CD subsequently (Falvey et al, 2005). In these derivatives, the cavity size and hydrophilic of the cyclodextrin headgroup increase. Oligo(ethylene oxide) amphiphiles can form bilayer, vesicoles, and nanoparticles.

\subsection{Cationic CD amphiphiles}

Donohue and coworkers reported the synthesis of CDs in which hydroxyl groups of oligo(ethylene oxide) were substitude with amine groups and their hydrochloride salts were used in gene delivery studies (Donohue et al, 2002) (Fig. 11).

\subsection{Anionic CD amphiphiles}

With alkylation of CDs by Declercq and coworkers (Leydet et al, 1998), achievement to versatile groups and so new structures were possible. For example Kraus et al with oxidation by osmium tetroxide in presence of 4-methyl morpholine prepared novel alcoholic stractures of mentioned allylic derivatives (Kraus et al, 2001). They converted the resulting diastreoisomeric diols to carboxylated CDs with oxidation (Fig. 12). 


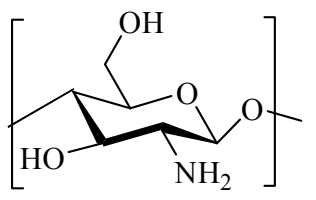

(24)<smiles>O=C1C=CC(=O)O1</smiles>

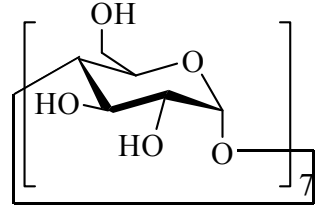

(26)

$$
\downarrow \begin{gathered}
\mathrm{Ph}_{3} \mathrm{P}, \mathrm{I}_{2} \\
\left(\mathrm{NH}_{2}\right)_{2} \mathrm{C}=\mathrm{S}
\end{gathered}
$$
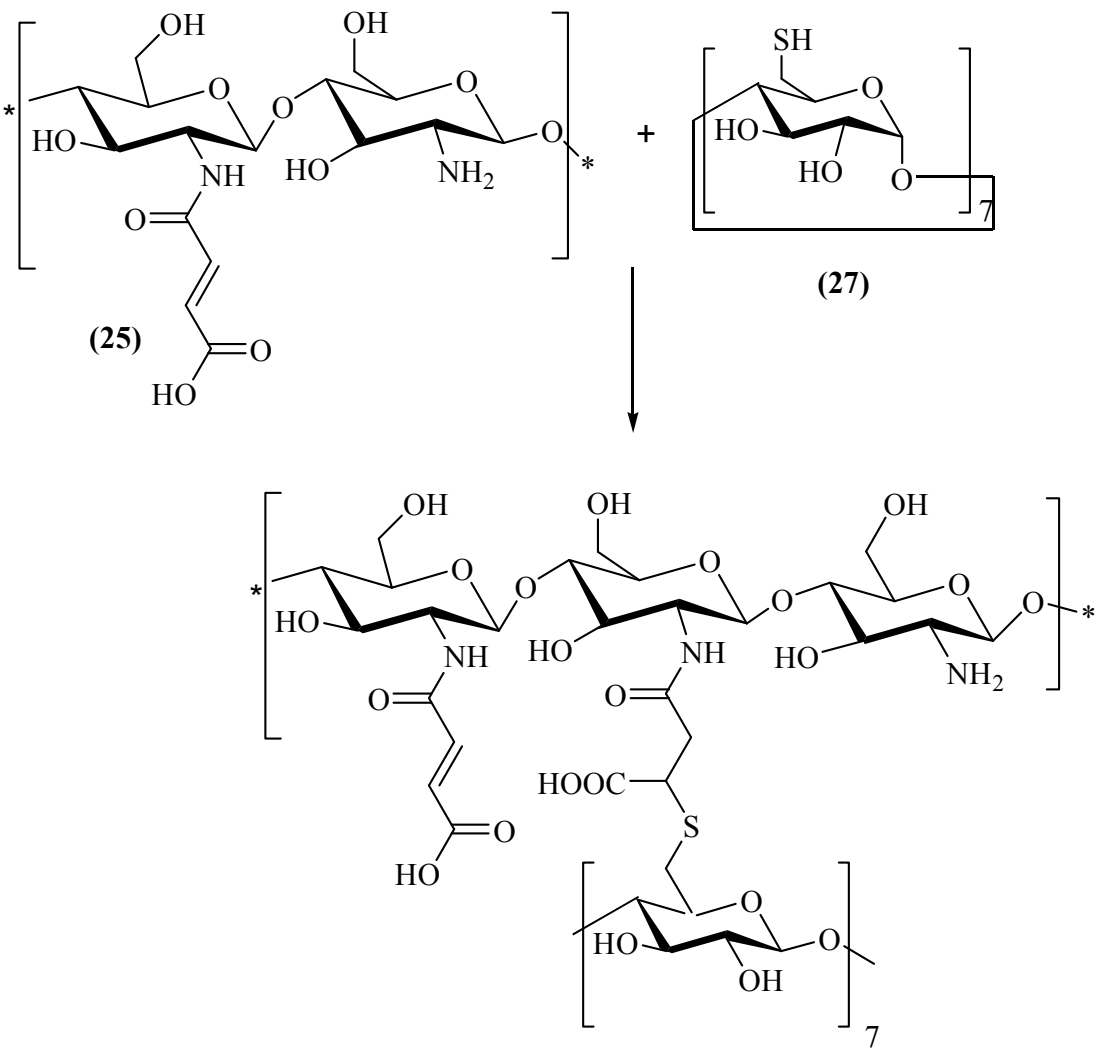

(28)

Figure 7. Synthetic path to Chitosan-cyclodextrin nanosphere 
The first sulfated amphiphilic CD synthesized by Dubes (Dubes et al, 2001, 2003). They produced compound (48) via esterification of silyl-protected CDs (45) with hexanoic anhydride at position 2 and 3. After removal of the silyl groups, the primary hydroxyl groups were sulfated by $\mathrm{SO}_{3}$.pyridine complex (Fig. 13).

\subsection{Flurinated CD amphiphiles}

Granjger and coworkers prepared the per tri fluromethyl thio- $\beta$-CD derivative (Granger et al, 2000), which formed monolayer at the air-water interface despite the short hydrophobic chains that applicable in oxygen delivery. Mono- di and per fluoro alkyl thio-CDs (Péroche et al, 2003, 2005) were made subsequently and demonstrated to self-organise into nanosphere in aqueous media, unlike their analogous alkylated derivatives that formed flat particle under same condition (Fig. 14).

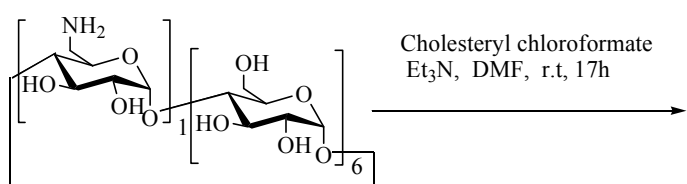

(29)
Succinic anhydride,DMF, $r . t, 3 \mathrm{~h}$ 3- $\alpha$-aminocholesterol, DIC/HOBt, DMF/THF,r.t, $48 \mathrm{~h}$.

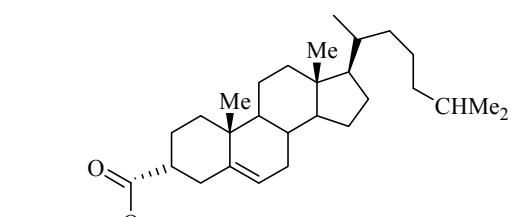

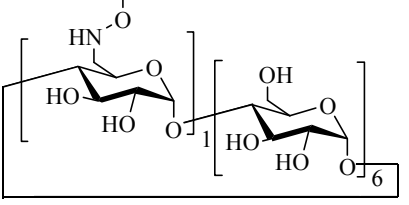

(30)

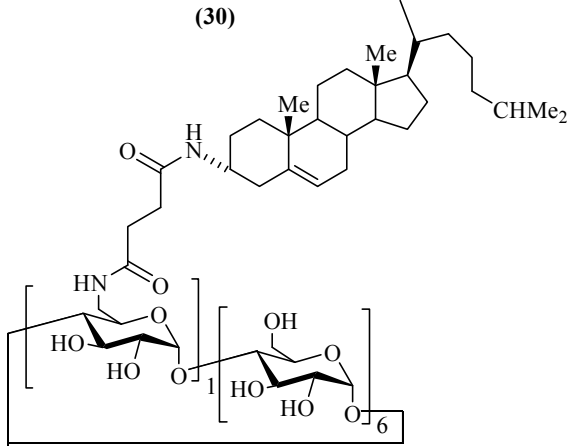

(31)

Figure 8. Synthesis of one of chlosteryl derivatives 
The synthesis of a $\gamma$-CD 6-per fluroalkyl ester was reported by Lim et al (Lim et al, 2006). CD was easily reacted with an excess heptafluoro butanoic acid and finally, compounds were formed that complexes with many substances for example surfactants.
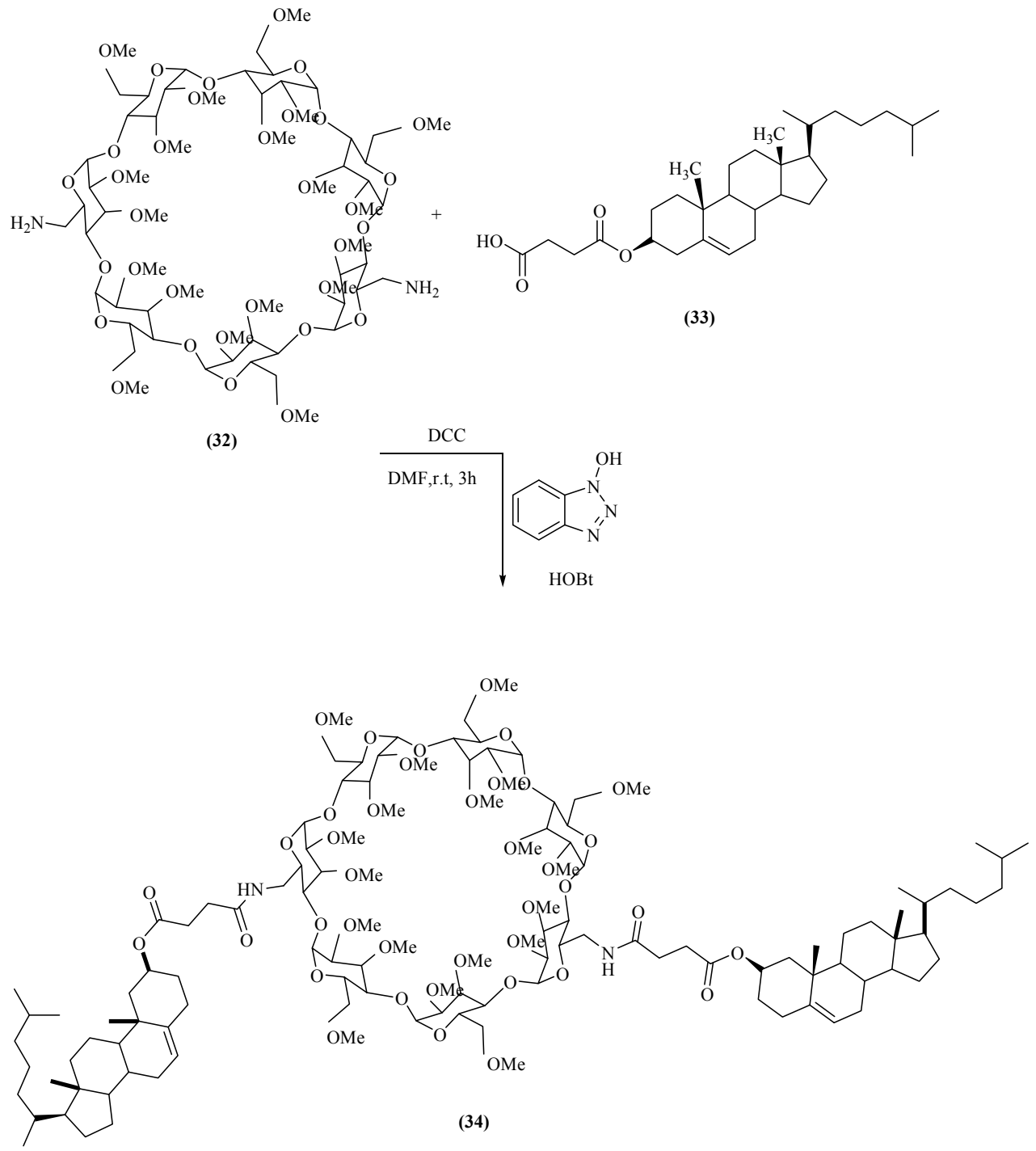

Figure 9. Synthesis of amphiphilic cyclodextrin that can act as similar to biological membrans 


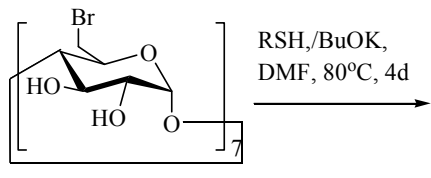

(35)

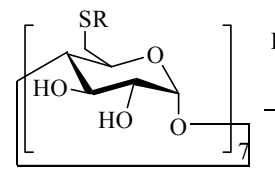

(36)

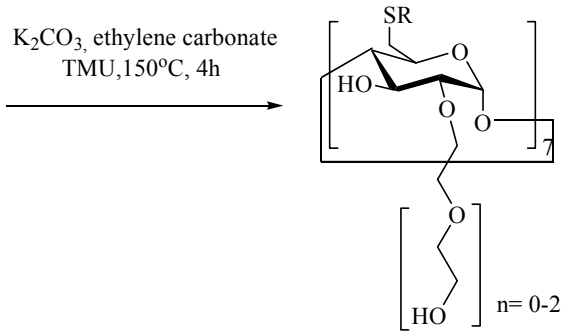

(37)

Figure 10. Synthesis of the first oligo(ethylene oxide) amphiphilic cyclodextrin
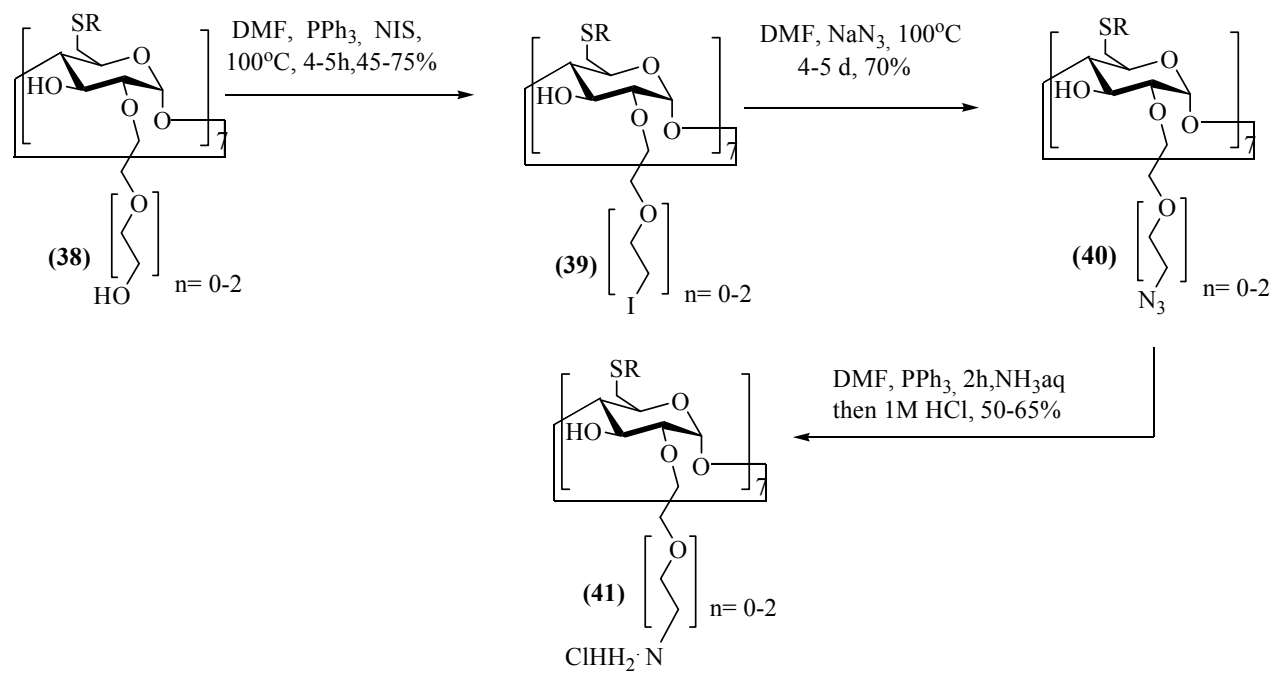

DMF, $\mathrm{PPh}_{3}, 2 \mathrm{~h}, \mathrm{NH}_{3} \mathrm{aq}$ then $1 \mathrm{M} \mathrm{HCl}, 50-65 \%$

Figure 11. One of synthetic path to cationic cyclodextrin amphiphiles 

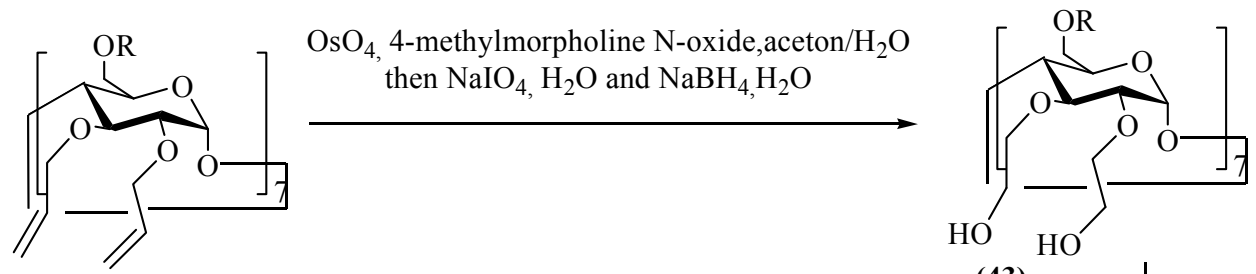

(42)

(43)

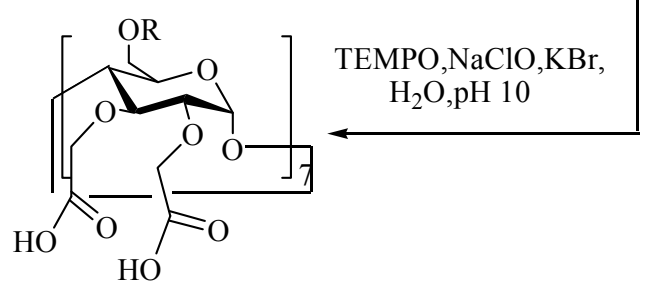

(44)

Figure 12. Osmium tetroxide beside to 4-methyl morpholine were used for synthesis of anionic cyclodextrin amphiphiles

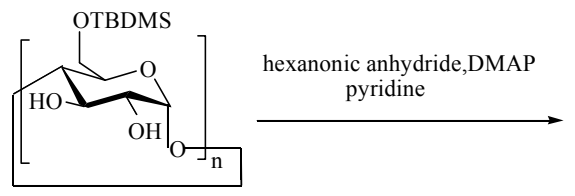

(45)

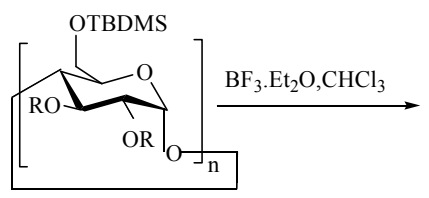

(46)

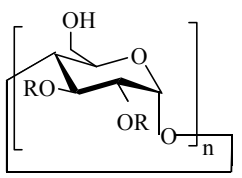

(47)

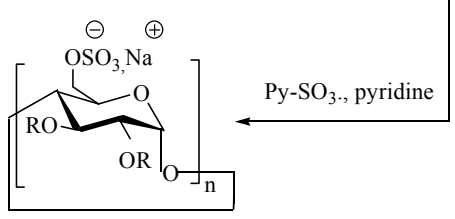

(48)

Figure 13. Synthesis of the first sulfated amphiphilic cyclodextrin 


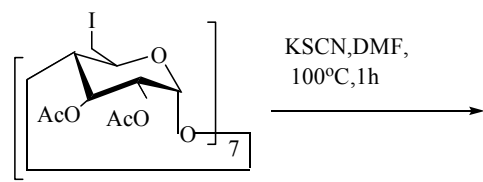

(49)

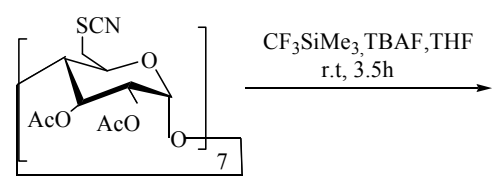

(50)

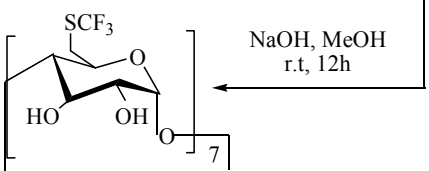

(52)

Figure 14. Synthesis of the per tri fluromethyl thio- $\beta-C D$ derivative by Granger et al

\subsection{Glycosylated CD amphiphilic}

Sallas and coworkers prepared CDs esterified on the C-2 and C-3 and glycosylated on the C6 position of glucose units (Sallas et al, 2004) (Fig. 15).

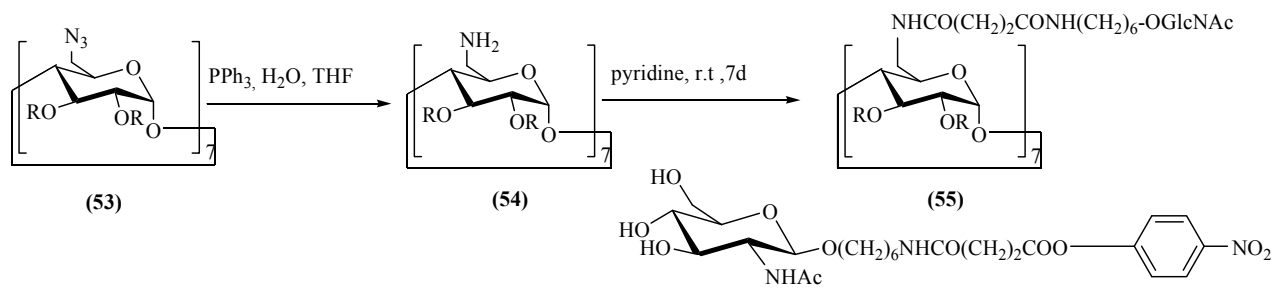

Figure 15. Preparation of glycosylated cyclodextrin amphiphilic

Glycosylation was occurred when a glucosamine having either a terminal amino group or an active ester group was reacted with amino CDs (Fig. 16).

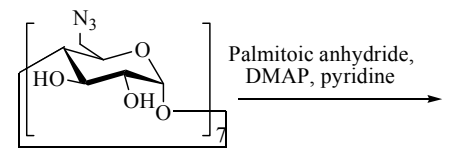

(56)

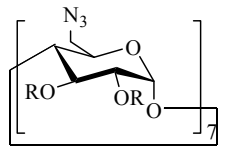

$\mathrm{R}=\mathrm{CO}\left(\mathrm{CH}_{2}\right)_{14} \mathrm{CH}_{3}$

(57)

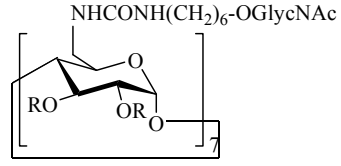

$\mathrm{R}=\mathrm{CO}\left(\mathrm{CH}_{2}\right)_{14} \mathrm{CH}_{3}$

(58)

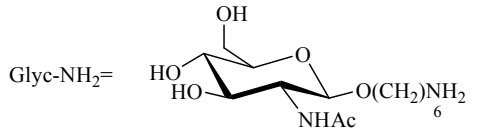

Figure 16. Glycosylation of amino cyclodextrins

A Staudinger reaction in pyridine and in presence of carbon dioxide led to the glycosylated CDs that having a urea function. 
Other type of glycosylated amphiphilic CDs have been prepared from oligo(ethylene oxide) CD amphiphile by Mazzaglia et al (Mazzaglia et al, 2004). Despite the existence of seven glycosyl groups, these compound aggregrated in water into vesicles (Fig. 17).
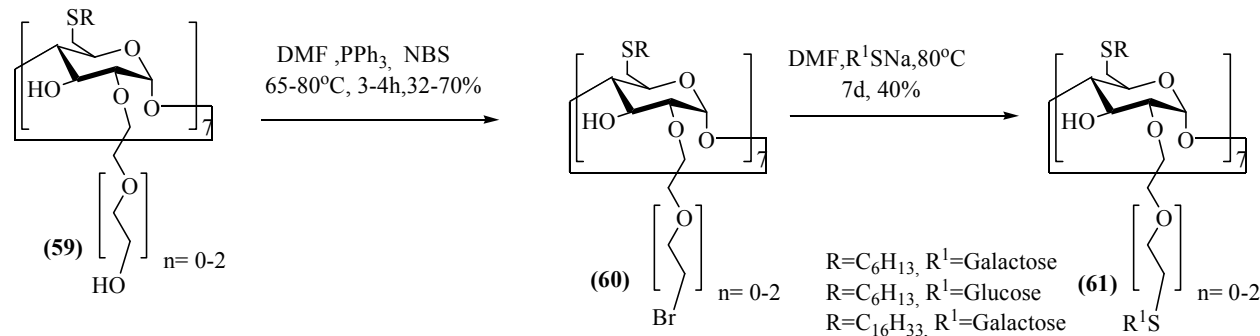

Figure 17. Glycosylation of oligo(ethylene oxide) cyclodextrin

Photochemical addition of sugar thiol to allylic groups on the CDs was another pathway for glycosylated CDs (Fulton \& Stoddart, 2001). The hydroxyl groups can be protected with silyl groups, then allylated the hydroxyl groups (on the position 2). This pathway has been further developed to create a variety of glycosylated amphiphilic CD such as (66) (Nicholas, 2005) (Fig. 18).

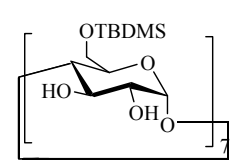

(62)

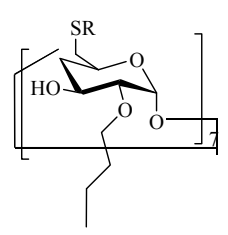

$\mathrm{SR}^{1}$

(66)

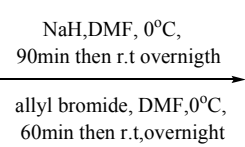

$60 \mathrm{~min}$ then r.t,overnight

acetylated $\mathrm{R}^{1} \mathrm{SH}, \mathrm{MeOH} /$ toluene, $\mathrm{N}_{2} \mathrm{UV}(\mathrm{l}=254 \mathrm{~nm})$, r.t.3 d, then $\mathrm{NaOMe}, \mathrm{MeOH} / \mathrm{DMF}$.r.t, 5-18 h

(63)

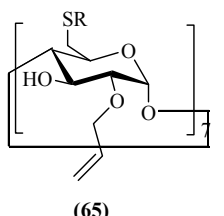

(65)

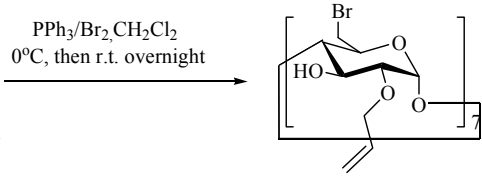

(64)

R-SH NaH, DMF, r.t.90 min then $80^{\circ} \mathrm{C}, 20 \mathrm{~min}$, r.t.

Figure 18. Photochemical addition, another path for synthesis of glycosylated cyclodextrin

\section{Molecular modeling in designing of host molecules}

Prediction of host-geust binding affinity could be made by calculating the binding energy. It could be down in molecular modeling software such as HyperChem (http://www.hyper.com/). In such software we can design and optimize the geometry of host and gust molecule separately and then by introducing the guest molecule in the cavity 
of host molecule, the geometry of the combined structure is optimized. Then the total energy of the host, guest and host-guest structures are separately calculated by single point command under one of the molecular calculation methods: molecular mechanics, semiempirical, ab-initio or DFT. By subtracting the single point energy of host-guest complex from sum of the host and guest energy, we can determine the binding energy. In this procedure there is some incompetency: Construction of the best geometry depends on oreintention loaded into the cavity of the host molecule. For example in fig.18 we can see two opposite and acceptable oreientaions of the dopamine in the cavity of the Heptakis [6$O$-(N-acetyl-L-Valyl)]- $\alpha$-cyclodextrin in the screen of the hyperchem software (Fig. 19). For this case, binding energy of both models must be separately calculated. The orientation with less energy is the preferable binding model for analyzing.

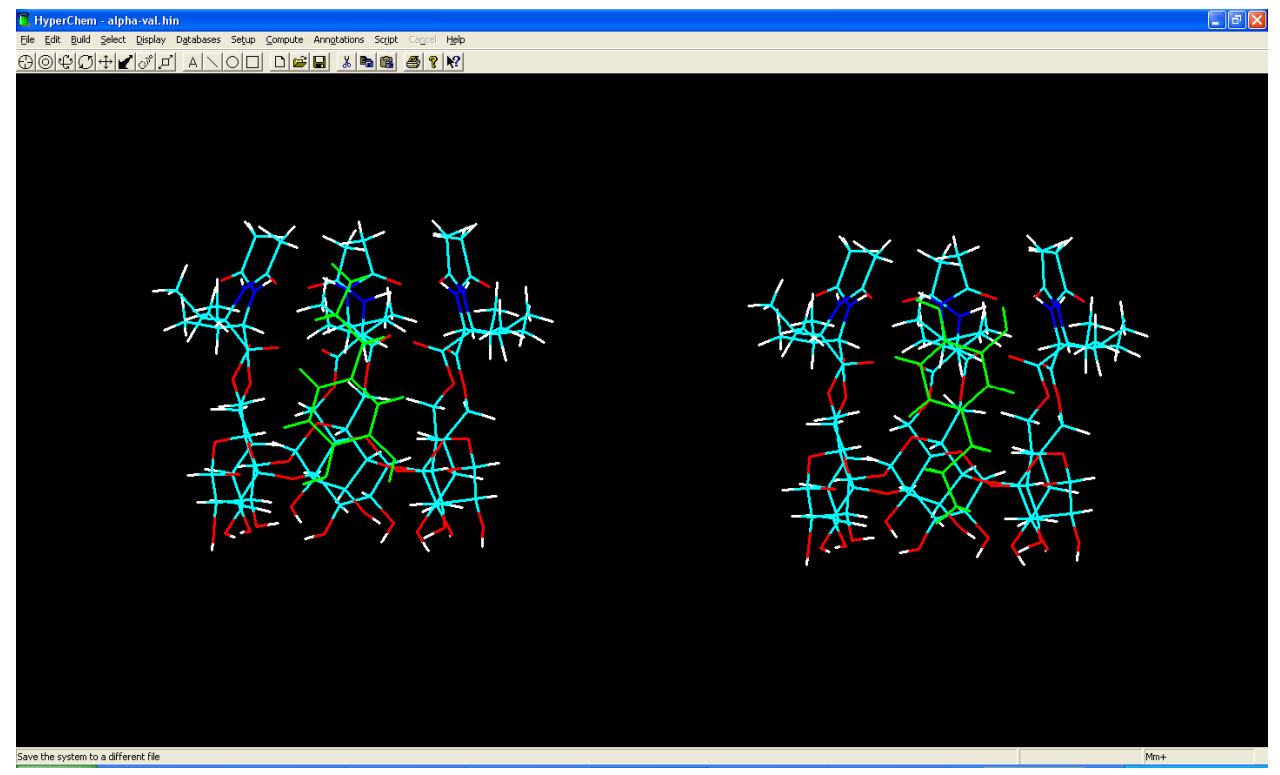

Figure 19. Stick view of the two binding model of dopamine loaded in the cavity of Heptakis [6-O-(Nacetyl-L-Valyl)]- $\alpha$-cyclodextrin in the screen of the hyperchem software.

In docking software, there is not such a mentioned limitation. In this software we can search all of the possible oreientation and rise to further acceptable binding conformers. This kind of molecular modeling operates based on the two combined calculation methods: local search and genetic algorithm known as Lamarckian Genetic Algorithm (LGA) (Morris et al, 1998). In this procedure the best binding conformation of the gust molecule based on the intermolecular interactions such as hydrogen binding, electrostatic force and ... is achieved.

AutoDockTools, also known as ADT, is an easy-to-use graphical front-end to the automated docking software packages AutoDock and AutoGrid (Phyton, 1999). ADT provides menus to: 
- $\quad$ set up a ligand (the 'moving' molecule to be docked) and write out a PDBQ file;

- $\quad$ set up a macromolecule (the 'fixed' molecule being docked to) and output a PDBQS file with solvation parameters;

- $\quad$ assign Kollman United Atom charged to a protein or peptide, or DNA or RNA;

- compute Gasteiger PEOE partial charges for small molecules or cofactors;

- add polar hydrogens, or 'merge' non-polar hydrogens;

- $\quad$ set up a grid box for atomic affinity grid maps and electrostatic potential maps around the target macromolecule (the box is a cubic space with definable center and dimension length);

- $\quad$ set various docking parameters;

- $\quad$ write GPF and DPF files (grid parameter and docking parameter files);

- launch AutoDock and AutoGrid calculations;

- $\quad$ read in DLG files (docking log files) and visualize AutoDock results;

- cluster and re-cluster docking results in various ways.

The ADT software is programmed for modeling of ligand-protein interactions. For small part of a protein (active site pocket) we set a restricted region as grid box, where docking operation performs in it. For host molecules with less than 4-5 KD, it could be defined so that all of the molecular structures located there (Fig. 20).
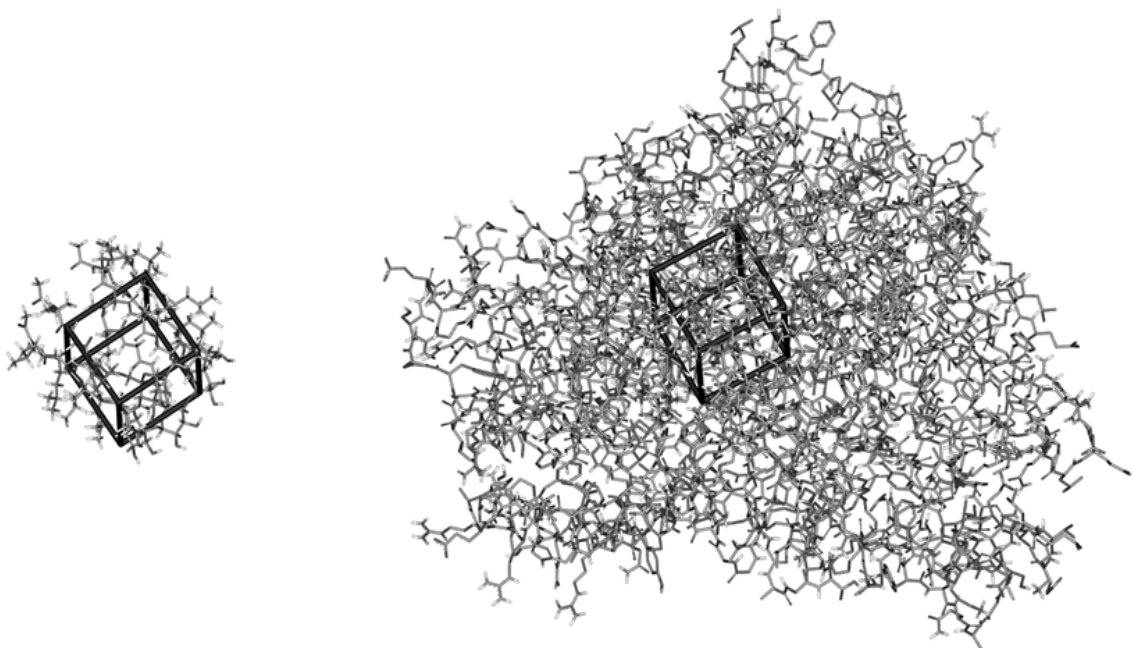

Figure 20. Comparison between the two host molecule grid boxes with the same size in ADT software: soybean 15-lipoxygenase enzyme (right) and a suggested host molecule with 2.6 KD molecular weight.

For reducing the formation of unfavorable binding conformer of gust molecules it is better to limit the size of the grid box around the internal space of the host molecule cavity. By doing the mentioned work, the external binding conformers will not originated by software and population of suitable conformers is increased. 
In modeling project, for a series of homolog guest molecules, it ought to be the docking results compare with the experimental data (extraction content, binding affinity, phase transferring ability with considering of lipophilic factors such as $\log \mathrm{D}$, and ... ). This comparison help us to reach the best binding conformation and it able us to predict the new structure of host molecule for better scavenging results. It lead us about how structure modifications, such as grafting of electronegative atoms, increase or decrease of lipophilic properties by introducing of hydrophobic substituents, could be made. Recently we have shown the ability of the mentioned calculating methods for a new series of peptide $\beta$ cyclodextrins as suitable host molecules for phase transferring of glucosamine (Seyedi et al, 2010).

\subsection{Amphiphilic peptide-cyclodextrins: Synthesis, designing and their utility as drug carrier: A novel experience}

Among the amphiphilic cyclodextrin, amphiphilic peptide-cyclodextrins (APCs) is one of the new and interesting case for studying in drug delivery field. In the aforementioned molecules, hydrophobic residues are aligned above the CD ring via amid or ester bonds and the cylindrical structure shape is observed in which the outer part is hydrophobic (duo to hydrophobic amino acids) while the head (CD ring) possess the hydrophilic nature. The structure was stabilized by cross intermolecular hydrogen bonds of amide groups. This molecular structure has ability for introducing the polar molecules into its cavity and transfer of them across the lipophil phases (Fig. 21).
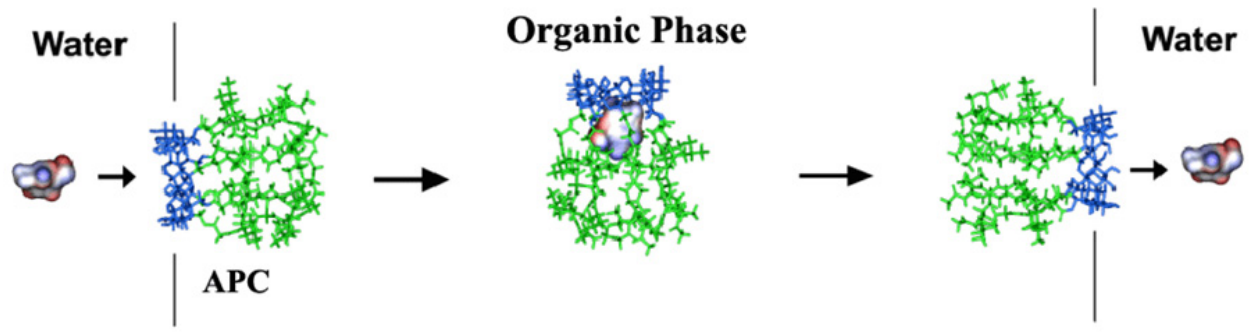

Figure 21. Transport of drug molecules across the organic phase by APC. The cyclodextrin ring and peptide moieties are distinguished by blue and green color respectively.

Our interested in design and synthesis of $\beta$-CD peptide derivatives emerges from the work of Imamura and co-workers in which preparation of amphiphilic compounds from peramino- $\beta$-CD using peptide chemistry was reported. The desired amphiphilic structures have been produced from ester linkage between all the C- 6 of $\beta-\mathrm{CD}$ and the carboxyl group of $N$ acetylated resides: $\mathrm{H}_{2} \mathrm{~N}$-Leu-COOH, $\mathrm{H}_{2} \mathrm{~N}-\mathrm{Leu}-\mathrm{Gly}-\mathrm{COOH}, \mathrm{H}_{2} \mathrm{~N}$-Leu-Gly-Leu-COOH and $\mathrm{H}_{2} \mathrm{~N}$-Leu-Gly-Leu-Gly-COOH (Fig. 22). 
In this molecular designing, L-leucine (Leu), the most lipophilic amino acid, was selected for extension of the cavity of $\beta$-CD and organizing an external lipophilic structure. Due to the inhibiting effect of $\mathrm{pH}$ on the amphiphilic property of the compounds, the $\mathrm{N}$-acetyl form of the aforementioned residues was used. To prevent steric hindrance adjust to leucine, Gly was selected as the preferred connector of the two residues.

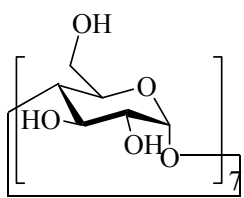

(67)

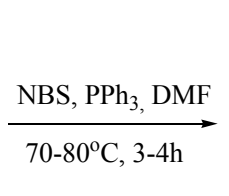

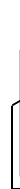

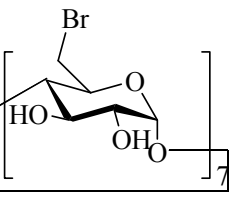

(68)

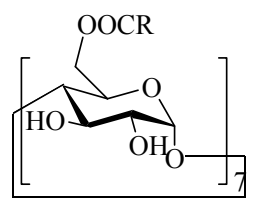

(69-72)<smiles>CC(=O)NC(CC(C)C)C(=O)[O-]</smiles>

(69)<smiles>CC(=O)NC(CC(C)C)C(=O)NCC(=O)NC(CC(C)C)C(=O)NCC(=O)O</smiles>

(72)

RCOO :<smiles>CC(=O)NC(CC(C)C)C(=O)NCC(=O)O</smiles>

(70)<smiles>CC(=O)NC(CC(C)C)C(=O)NCC(=O)NC(CC(C)C)C(=O)O</smiles>

(71)

Figure 22. General procedure for the synthesis of amphiphilic peptide $\beta$-CDs (69-72).

Binding behavior was studied using glucosamine as a guest molecule. The relative binding affinity of 69-72 toward glucosamine was measured using a phase extraction method. the decrease in concentration of aqueous glucosamine $(\mathrm{pH} 7.4)$ after shaking for $12 \mathrm{~h}$ with a lipid phase (octanol) containing 69-72 and $\beta$-CD was determined and reported as extraction content (\%E).

the equilibrium constant of extraction could be defined as the binding constant $\left(\mathrm{K}_{\mathrm{b}}\right)$ :

$$
\begin{aligned}
& \mathrm{K}_{b}=([\text { host}-\mathrm{Glu}]) /([\mathrm{Glu}][\text { host }] \\
& \text { host }+ \text { Glu } \rightleftarrows \text { host-Glu }
\end{aligned}
$$

The observed glucosamine binding constants $\left(\mathrm{K}_{\mathrm{b}}\right)$ of 69-72 are outlined in Table 2.

In the other experiment, phase transfer of glucosamine by 69-72 and $\beta$-CD was determined. In this work the tendency of each compound for glucosamine transferring between two aqueous phases, separated by octanol, was measured (Fig. 23). Two stirred aqueous phases $(\mathrm{pH} 7.4)$, in which one of them (primary phase) contained glucosamine (25 mM), were 
connected through octanol, containing test compound (69-72 and $\beta-\mathrm{CD} ; 5 \mathrm{mM}$ ), without any solvent diffusion. After $24 \mathrm{~h}$ the glucosamine concentration of the intact aqueous phase (secondary phase), was determined. The ratio of glucosamine concentration of the primary and secondary phases was recorded as phase transferring extent $(\% \mathrm{~T})$.

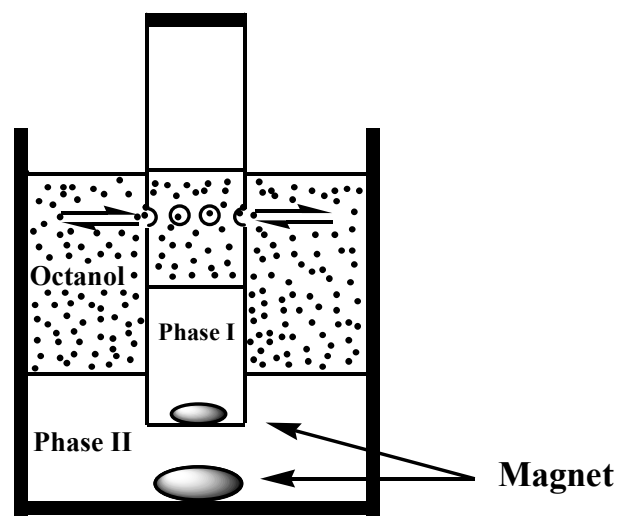

Figure 23. Schematic presentation of the apparatus used for phase transfer experiment

\begin{tabular}{ccc}
\hline Case & $\% \mathrm{E}$ & $\% \mathrm{~T}$ \\
\hline 69 & $24.4 \pm 0.9$ & $1.62 \pm 0.3$ \\
70 & $23.8 \pm 2.2$ & $1.50 \pm 0.2$ \\
71 & $28.6 \pm 1.8$ & $3.49 \pm 0.3$ \\
72 & $26.3 \pm 1.2$ & $1.63 \pm 0.4$ \\
& & \\
CD & $0.40 \pm 0.2$ & $0.74 \pm 0.1$ \\
& & \\
Ctr. & $0.21 \pm 0.1$ & $0.43 \pm 0.1$ \\
\hline
\end{tabular}

Table 1. Extraction and phase transferring percentage of glucosamine (\%E and \%T respectively) by compounds 69-72.

Among the tested compounds, a modest phase transfer was observed for 71 , while the experiments with 69-70 and 72 showed worse results (Table 1). Phase transfer of glucosamine by $\beta$-CD was significantly lower. 
To explore the origin of these effects, the octanol-water disturbtion coefficient $(\log D)$ of 69 72 was measured using shake flask method (Griffin et al, 1999). On the other hand by considering the $\log \mathrm{D}$ values, the phase transfer results of $69-72$ could be rationalized. It was concluded that more lipophilic host molecule $(71: \log \mathrm{D} 1.57)$ has a higher capability for transferring glucosamine in determined period time.

To complete the study, the binding affinity of glucosamine toward 69-72 was calculated and reported as estimated binding free energy $(\Delta \mathrm{Gb})$. In this section, the 3D structures of 69-72 were modeled via grafting the desired residues on all primary hydroxyls of $\beta-\mathrm{CD}$ crystal structure followed by geometry optimization (PM3 methods). In the modeled molecules, residues are aligned above the $\beta$-CD ring and the cylindrical structure shape is observed in which the outer part is hydrophobic while the head ( $\beta-C D$ ring) possess the hydrophilic nature. The structure was stabilized by cross intermolecular hydrogen bonds of amide groups. The binding affinity was estimated in AuoDockTools software using autodock4.0 program (Python, 1999). 100 docked conformers of glucosamine were generated in ADT software for each of 69-72. The detailed assessment of all 100 docked models revealed as followings: $100 \%$ of docking results had nearly identical orientations in the $\beta$-CD ring with average $\Delta \mathrm{G}^{\circ}$ b of $-5.81 \mathrm{kcal} / \mathrm{mol}$ for 69 ; while for $70,68 \%$ of docking results had nearly identical orientations in the $\beta-\mathrm{CD}$ ring and $32 \%$ in the pocket formed by the residues with average $\Delta \mathrm{Gb}$ of -6.13 and $-6.25 \mathrm{kcal} / \mathrm{mol}$ respectively; for $71,58 \%$ of docking results had nearly identical orientations in $\beta$-CD ring and $42 \%$ in the mentioned pocket with average $\Delta \mathrm{Gb}$ of -5.62 and $5.45 \mathrm{kcal} / \mathrm{mol}$ respectively and finally for $72,69 \%$ of docking results had nearly identical orientations in $\beta$-CD ring and $31 \%$ in the mentioned pocket with average $\Delta \mathrm{Gb}$ of -6.14 and $6.08 \mathrm{kcal} / \mathrm{mol}$ respectively (table 2). Due to the orientation mentioned above, the docked conformers displayed hydrogen bonds with hydroxyl and amides of the sugars and residues in 69-72. Considering $\Delta \mathrm{G}_{\mathrm{b}}^{\mathrm{o}}=-\mathrm{RT} \ln \mathrm{K}_{\mathrm{b}}$ and equation (1), the high similarity between experimental and theoretical results $\left(\Delta \mathrm{G}^{\mathrm{o}} \mathrm{b}\right.$ and $\Delta \mathrm{Gb}$ respectively) was anticipated.

\begin{tabular}{lcccc}
\hline Compd. & $\Delta \mathrm{G}_{\mathrm{b}}$ & $\Delta \mathrm{G}_{\mathrm{b}}^{\mathrm{o}}$ & $\mathrm{K}_{\mathrm{b}}$ & $\log \mathrm{D}$ \\
\hline 69 & $-5.81 \pm 0.13$ & -2.62 & 84.2 & $1.17 \pm 0.07$ \\
70 & $-6.17 \pm 0.22$ & -2.60 & 80.8 & $1.05 \pm 0.04$ \\
71 & $-5.55 \pm 0.26$ & -2.79 & 110.8 & $1.57 \pm 0.05$ \\
72 & & & & \\
& & & & \\
& & & & \\
\end{tabular}

Table 2. Octanol-water disturbtion coefficient $(\log D)$, experimental free energy of binding $\left(\Delta \mathrm{G}^{\mathrm{o}} \mathrm{b}\right)$, binding constant $\left(\mathrm{K}_{\mathrm{b}}\right)$ and average of estimated free energy of binding $(\Delta \mathrm{Gb})$ for compounds 69-72. 

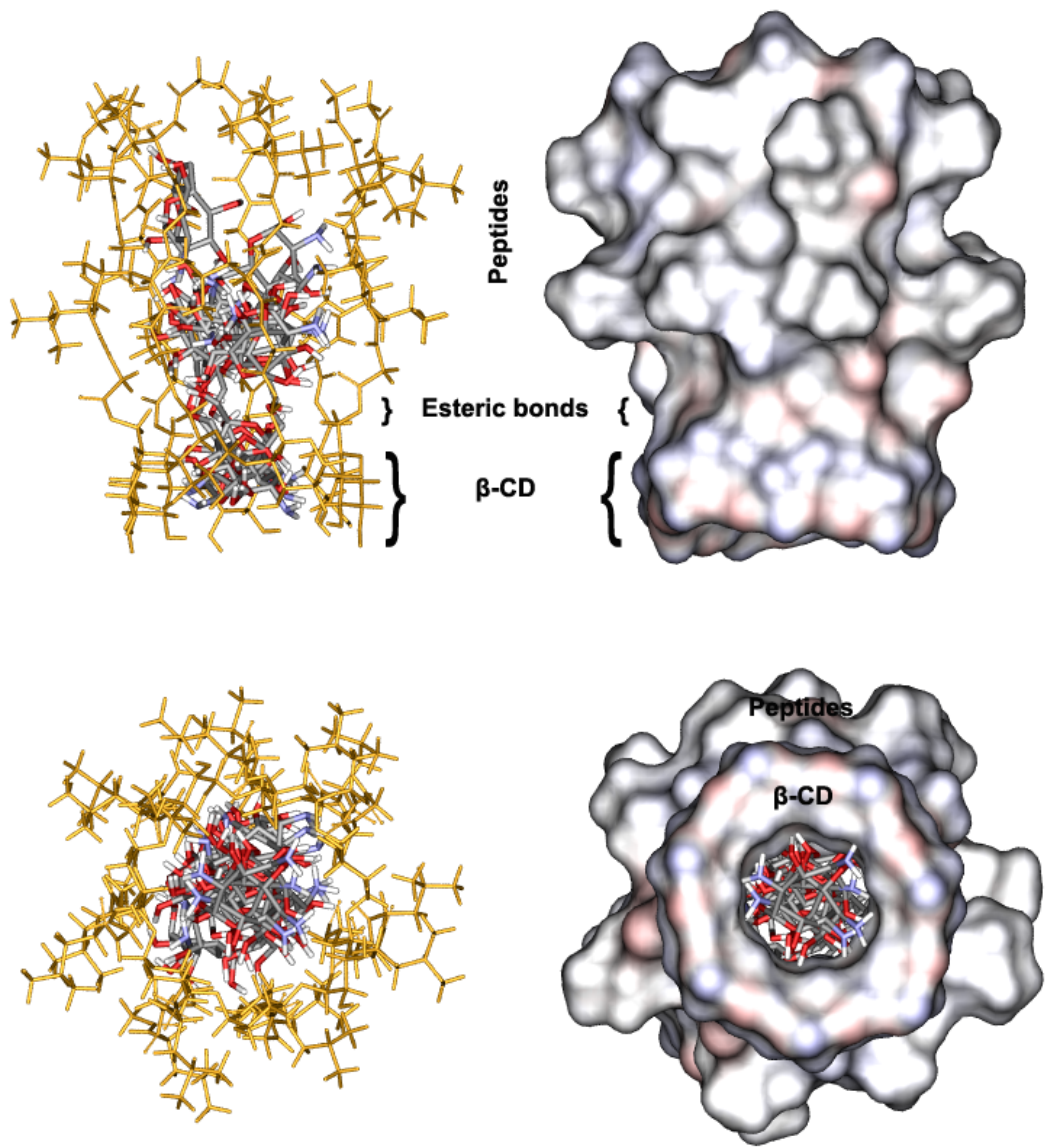

Figure 24. All of the Docked models of glucosamine in the cavity of 72 . The below figure represents the cross view of docked models in $3 \mathrm{~d}$ cavity.

Docking results of 69-72, showed that the binding free energy of glucosamine for all of the host molecules are almost equal and the docked models are mainly located in $\beta$-CD cavity. This could explain why the extraction contents and $\mathrm{K}_{\mathrm{b}}$ of 69-72 are similar.

Phase transfer properties of 69-72 is mainly depend on the external lipophilic character of their cavity while the host molecules have similar binding affinity toward glucosamine, the more lipophilic one (71), would transfer higher quantities of the guest molecule.

This kind of molecular modeling method operated based on the two calculation methods: local search and genetic algorithm. In this It could be useful for further design of host molecules. Recently we have show the ability of the menthioned calculating methods for a new series of peptide- $\alpha$-cyclodextrins as a suitable host molecules for extracting of dopamine (Seyedi et al, 2011). 


\section{Conclusion}

In summary, we have designed and synthesized a new series of hydrophobic peptide $\beta$ cyclodextrins as a phase transfer carrier for glucosamine. These types of cage-molecules could be a precursor for designing and synthesis of other similar molecules as carriers for desired biological compounds in the future. Considering the external hydrophobicity and terminal hydrophilicity of these molecular structures, it would be hypothesized, that the natural capacity of these compounds to locate in the bilayer membrane of the cells, act as a channel for transferring special compounds.

By using of the molecular modeling techniques, down by the molecular interaction stimulator softwares, we can design a suitable host APC for recognition and scavenging a desired guest molecule. The mentioned method helps us for predicting which of the cyclodextrin types ( $\alpha, \beta$ or $\gamma$ type), how long of the peptide chains and what kinds of the amino acids could be suitable for the synthesis of an efficient host APC. In this chapter we discussed about the principles of the APCs modeling, host-guest interactions, synthetic methods and the application of them in drug delivery systems.

\section{Author details}

Hamid Sadeghian

Department of Laboratory Sciences, School of Paramedical Sciences, Mashhad University of Medical Sciences, Mashhad, Iran

Atena Jabbari

Department of Chemistry, School of Sciences, Ferdowsi University, Mashhad, Iran

\section{References}

Auto Dock Tools (ADT), the Scripps Research Institute, 10550 North Torrey Pines Road, La Jolla, CA 92037-1000, USA Python, M. F. S. ( 1999). Python: A Programming Language for Software Integration and Development. J. Mol. Graphics Mod., Vol.17,No.1, pp. 57-61, ISSN 1093-3263 http://www.scripps.edu/pub/olson-web/doc/autodock

Auze'ly-Velty, R.; Djedaïni-Pilard, F.; De'sert, S; Perly, B. \& Zemb T. (2000).Micellization of hydrophilic modified cyclodextrins.1. micellar structure. Langmuir, Vol.16, No.8, pp. 3727-3734, ISSN 0743-7463

Auzély-Velty, R.; Perly, B.; Taché, O.; Zemb, T.; Jéhan, P.; Guenot, J.-P. Dalbiez, P. \& Djedaïni-Pilard, F. (1999). Carbohydr. Res. Vol. 318, No.1-4, pp. 82-90, ISSN 0008-6215

Collat, M.; Garcia-Moreno, M. I.; Fajolles, C.; Roux, M.; Mauclaire, L. \& Mallet, J. M. (2007). Bis antenna amphiphilic cyclodextrins: the first examples. Tetrahedron. Lett, Vol.48, No.48, pp. 8566-8569, ISSN 0040-4039

Donohue, R.; Mazzaglia, A.; Ravoo, B. J. \& Darcy, R. (2002). Cationic - $\beta$-cyclodextrin bilayer vesicles. Chem.Commn. Vol.2002, No.23, pp. 2864-2865, 0022-9936 
Dubes, A.; Degobert, G.; Fessi, H. \& Parrot-Lopez , H. (2003). Synthesis and characterization of sulfated amphiphilic $\alpha$ - $\beta$-and $\gamma$-cyclodextrins: application to the complexation of acyclovir. Carbohydr. Res.Vol.338, No.21, pp. 2185- 2193, ISSN 0008-6215

Dubes, A.; Parrot-Lopez, H.; Abdelwahed, W.; Degobert, G.; Fessi, H.; Shahgaldian , P. \& Coleman, A.W. (2003). Scanning electron microscopy and atomic force microscopy imaging of solid lipid nanoparticles derived from amphiphilic cyclodextrins. Eur. J. Pharm. Biopharm, Vol.55, No.3, pp. 279-282, ISSN 0939-6411

Dubes, A.; Bouchu, D.; Lamartine, R. \& Parrot-Lopez, H. (2001). An efficient region-specific synthesis route to the multiply substituted acyl-sulphated $\beta$-cyclodextrins. Tetrahedron Lett, Vol.42, No.11, pp. 9147-9151, ISSN 0040-4039

Falvey, P.; Lim, C. W.; Darcy, R.; Revermann, T.; Karst, U. M.; Giesbers, A.; Marcelis, M.; Lazar, A.; Coleman, A. W. D.; Reinhoudt, N. B. \& Ravoo , J. (2005). Bilayer vesicles of amphiphilic cyclodextrins: host membranes that recognize guest molecules. Chem. Eur. J, Vol.11, No.6, pp. 1171-1180, ISSN 0947-6539

Fulton, D. A. \& Stoddart, J. F. (2001). Synthesis of cyclodextrin-based carbohydrate clusters by photoaddition reactions. J. Org. Chem, Vol.66, No.25, pp. 8309- 8319, ISSN 0022-3263

Granger, C. E.; Félix, C. P.; Parrot-Lopez, H. P.\& Langlois B. R. (2000). Flurine containing $\beta$ cyclodextrin: a new class of amphiphilic carriers. Tetrahedron Lett, Vol.41, No.48, pp. 9257-9260, ISSN 0040-4039

Greenhall, M.H.; Lukes, P.; Kataky, R.; Agbor, N.E.; Badyal, J.P.S;. Yarwood, J.; Parker, D. \& Petty, M.C. (1995). Monolayer and multilayer flims of cyclodextrins substituted with two and three alkyl chains. Langmuir,Vol.11, No.10, pp. 3997-4000, ISSN 0743-7463

Griffin, S.; Wyllie, S. G. \& Markham, J. (1999). Determination of octanol-water partition coefficient for terpenoids using reverswd-phase high-performance liquid chromatography. J. Chromatogr. Vol.846, No.2, pp.221-228.

Hedges, A.R. (1998). Industrial applications of cyclodextrins. Chem. Rev, Vol.98, No.5, pp. 2035-2044, ISSN 0009-2541

Imamura, K.; Ikeda, H. \& Ueno, A. (2002). Enhanced binding ability of $\beta$-cyclodextrin bearing seven hydrophobic chains each with a hydrophilic end group. Chem. Lett, Vol.31, No.5, pp. 516-517, ISSN 0336-7022

Israelachvilli, J. N. (1985). Intermolecular and Surface Forces: With Application to Colloidal and Biological Systems, Academic Press, New York. (b) Fuhrhop, J.-H. \& Koning, J. (1994). Membranes and Molecular Assemblies: The Synkinetic Approach, Royal Society of Chemistry, Cambridge.

Kawabata, Y. ; Matsumoto, M.; Tanaka, M.; Takahashi, H.; Irinatsu, Y.; Tamara, S.; Tagaki, W.; Nakahara , H. \& Fukuda, K. (1986). Formation and deposition of monolayers of amphiphilic $-\beta$-cyclodextrin derivatives. Chem. Lett.Vol.11, No.12, pp. 1933-1934, ISSN 1157-1489

Kraus, T.; Budesinsky, M .\& Zavada,J. (2001). General approach to the synthesis of persubstituted hydrophilic and amphiphilic cyclodextrin derivatives. J. Org. Chem, Vol.66, No.13, pp. 4595-4600, ISSN 0022-3263

Leydet, A.; Moullet, C.; Roque, J. P.; Witvrouw, M.; Pannecouque, C.; Andrei, G.; Snoeck, R. Neyts, J.; Schols, D. \& De Clercq, E. (1998). Polycationic compound and polyzwitterionic 
compound derived from cyclodextrins as inhibitors of HIVtransmission. J. Med. Chem, Vol. 41, No.25, pp. 4927-4932, 0022-2623

Lim, K. T.; Ganapathy, H. S., Lee, M. Y.; Yuvaraj, H.; Lee, W.-K. \& Heo, H. (2006). Afacil one-pote synthesis of novel amphiphilic perfluoroalkyl ester functionalized $\gamma$ cyclodextrin and complex formation with anionic surfactants. J. Fluorine Chem, Vol.127, No.6, pp. 730-735, ISSN 0022-1839

Ling, C.-C. \& Darcy, R. (1993). 6-S- hydroxyethylated 6- thiocyclodextrins: expandable host molecules. J. Chem. Soc. Chem. Commun, Vol.1993, No.1, pp. 203-205, ISSN 0022-4936

Ling, C.C.; Darcy, R. \& Risse, W. (1993). Cyclodextrin liquid crystals: synthesis and selforganization of amphiphilic thio- $\beta$-cyclodextrins. J. Chem. Soc. Chem. Commun. Vol.1993, No.5, pp. 438-440, ISSN 0022-4936

Mazzaglia, A.; Donohue, R.; Ravoo, B. J. \& Darcy, R. (2001). Novel amphiphilic cyclodextrins: graft- synthesis of heptakis (6-alkylthio-6-deoxy)- $\beta$-cyclodextrin 2oligo(ethylene glycol) conjugate and their $\omega$-halo derivatives. Eur. J. Org. Chem, Vol.2001, No.9, pp. 1715-1721, ISSN 1434-193X

Mazzaglia, A.; Forde, D.; Garozzo, D.; Malvagna, P.; Ravoo, B. J. \& Darcy, R. (2004). Multivalent binding of galactosylated cyclodextrin vesicles to lectin. Org. Biomol. Chem, Vol.2, No.7, pp. 957-960.

Mc Nicholas, S .( 2005). Ph. D. Thesis, University College Dublin, Dublin, Ireland.

Morris, GM.; Goodsell, DS.; Halliday, RS.; Huey, R.; Hart, WE.; Belew, RK. \& Olson, JA. (1998). Automated docking using a lamarckian genetic algoritm and an empirical bonding free energy function. J Comput Chem, Vol.19, No.14, pp. 1639-1662, ISSN 1096987X

Parrot-Lopez, H.; Ling, C.C.; Zhang, P.; Baszkin, A.; Albrecht, G.; De Rango, C. \& Coleman, A.W. (1992). Self-assembling systems of the amphiphilic cationic per-6- amino-betacyclodextrin 2,3-Di-O-alkyl ethers. J. Am. Chem. Soc. Vol.114, No.13, pp. 5479-5480, ISSN $0002-7863$

Péroche, S. \& Parrot-Lopez, H. (2003). Novel fluorinated amphiphilic cyclodextrin derivatives: synthesis of mono-, di- and heptakis-(6-deoxy-6- per fluoroalkylthio)- $\beta$ cyclodextrin. Tetrahedron Lett. Vol.44, No.2, pp. 241-245, ISSN 0040-4039

Péroche, S.; Degobert, G.; Putaux, J.-L.; Blanchin, M.-G.; Fessi, H. \& Parrot-Lopez, H. (2005). Synthesis and characterization of novel nanospheres made from amphiphilic perfluoroalkylthio- $\beta$-cyclodextrins. Eur. J. Pharm. Biopharm, Vol.60, No.1, pp. 123-131, ISSN 1434-193X

Prabaharan, M. \& Gong, S. (2007). Novel thiolated carboxymethyl chitosan-g-b-cyclodextrin as mucoadhesive hydrophobic drug delivery carriers. Carbohydrate Polymers, Vol.73, No.1, pp. 117-125, ISSN 0144-8617

Ravoo, B. J. \& Darcy, R. (2000). Cyclodextrin bilayer vesicles. Angew. Chem. Int. Ed. Vol.39, No.23, pp. 4324-4326, ISSN 1433-7851

Ravoo, B.J. \& Darcy, R. (2000). Cyclodextrin bilayer vesicles. Angew. Chem. Int. Ed. Vol.39, No.23, pp. 4324-4326, ISSN 1433-7851 
Sallas, F.; Niikura, K. \& Nishimura S.-I. (2004). Apractical synthesis of amphiphilic cyclodextrins fully substituted with sugar residue on the primary face. Chem. Commun, Vol.2004, No.5, pp. 596-597, ISSN 0022-9936

Seyedi, S. M.; Sadeghian, H.; Jabbari, A.; Assadieskandar, A. \& Momeni, H. (2010). Design and synthesis of a new series of amphiphilic peptide- $\beta$-cyclodextrins as phase transfer carriers for glucosamine. Tetrahedron, Vol.66, No.34, pp. 6754-6760, ISSN 0040-4020

Seyedi, S. M.; Sadeghian, H.; Jabbari, A.; Assadieskandar, A. \& Momeni, H. (2011). Synthesis of new series of $\alpha$-cyclodextrin esters as dopamine carrier molecule. Bioorg. Med. Chem, Vol.19, No.14, pp. 4307-4311, ISSN 0968-0896

Skiba, M.; Duche'ne, D.; Puisieux, F. \& Wouessidjewe D.(1996). Development of a new colloidal drug carrier from chemically modified cyclodextrins: nanospheres and influence of physicochemical and technological factores on particle size. Int. J. Pharm, Vol.129, No.2, pp. 113-121, ISSN 0975-1491

Szejtli, J. (1998). Introduction and general overview of cyclodextrin chemistry. Chem. Rev, Vol.98, No.5, pp. 1743-1754, ISSN 0009-2541

Uekama, K.; Hirayama, F. \& Irie, T. (1998). Cyclodextrin drug carrier systems. Chem. Rev, vol.98, No.5, pp. 2045-2076, ISSN 0009-2541

Wang, J.; Zong, J.-Y.; Zhao, D.; Zhuo, R.-X. \& Cheng, S.-X. (2011). In situ formation of chitosan-cyclodextrin nanospheres for drug delivery. Colloids and Surfaces B: Biointerfaces, Vol. 87, No.1, pp. 198- 202, ISSN 0927-7765

Wazynska, M.; Temeriusz, A.; Chmurski, K.; Jurczak. J. \& Bilewicz, R. (2000). Synthesis and monolayer behavior of amphiphilic per (2,3-di-O-alkyl) - and $\beta$ - cyclodextrins and hexakis (6-deoxy-6-thio-2,3-di-O-pentyl) $-\alpha$ - cyclodextrin at an air-water interface. Tetrahedron Lett, Vol.41, No.47, pp. 9119-9123, ISSN 0040-4039

Woussidjewe, D.; Skiba, M., Leroy-Lechat, F.; Lemos-Senna, E.; Puisieux, F. \& Duchene D. (1996). A new concept in drug delivery based on skirt-shaped cyclodextrin aggregates, present state and future prospects. STP Pharma Sci. Vol.6, No.1, pp. 21-28.

Zhang, G.; Liang, F.; Song, X.; Liu, D.; Li, M. \& Q.; Wu. (2011). New amphiphilic biodegradable- $\beta$ - cyclodextrin/poly cyclodextrin/poly(L-leucine) copolymers, Synthesis, characterization, and micellization. Carbohydrate Polymers, Vol.80, No.3, pp. 885-890, ISSN 0144-8617 